\title{
Sastra, Hoax, dan Kritik yang HOTS ${ }^{1}$ \\ Oleh \\ Teguh Trianton ${ }^{2}$
}

Karya sastra merupakan objek yang otonom, lantaran ia boleh dibaca siapa saja dengan berbagai pretensi, niatan, dan cara baca yang bebas dan beragam. Namun, pada saat yang sama (dibaca) otonomi karya sastra justru hilang. Ia tidak benar-benar bebas nilai atau menjadi objek yang tunggal sehingga hanya memiliki satu kemungkinan tafsir. Sastra disebut otonom hanya pada saat ia dianggap sebagai objek materi, artefak atau benda mati. Pada saat sastra dicipatakan (ditulis) dan diapresiasi oleh pembaca (audien), ia sudah bukan objek yang otonom.

Proses penciptaan karya sastra bertalian erat dengan berbagai persoalan dan teks budaya yang melatari kehidupan sastrawan. Meski sastrawan bebas menuliskan sesuatu, namun ia mesti melakukan interaksi dengan berbagai teks. Dengan demikian, sastra yang dibuat mendapatkan relevansinya dengan berbagai jaringan budaya yang dapat membantu pembaca mengidentifikasi pesan atau maksud pengarang.

Di tangan pembaca, sastra yang diapresiasi juga mengalami prosedur serupa. Ia tidak benar-benar otonom. Membaca sastra adalah upaya menempatkan teks di tengah-tengah jaringan teks yang berkelindan. Membaca sastra merupakan ikhtiar menciptakan kompromi teks untuk menentukan nilai dan pesan yang tersembunyi di dalamnya. Prosedur kompromi ini dilakukan dengan cara menukar wacana yang dimiliki pembaca dengan wacana yang dimiliki pengarang yang dituang dengan estetika tertentu dalam karya sastra. Di tangan pembaca, karya sastra berhadapan dengan beragam teks budaya yang melingkupinya.

\section{Sastra dan Hoax}

Karya sastra dibangun melalui proses reproduksi sistem tanda yang beragam, bertingkat, tidak tunggal, dan interteks. Konstruksi wacana yang terdapat di dalamnya tidak independen, tetapi saling berhubungan dengan berbagai wacana di luarnya. Pada tahap inilah, sastra menjadi sebuah hoax yang etik dan estetik. Sastra tidak pernah benar-benar mampu menjadi medium bagi sastrawan untuk mewadahi gagasannya. Selalu ada potensi pembiasaan pesan dan nilai di dalamnya atau hoax.

Sastra menjadi hoax karena hakikat sastra merupakan karya seni. Yang dimaksud hoax di sini adalah seni menyampaikan maksud dengan estetika bahasa sehingga menimbulkan pertentangan antara kebenaran dan dusta dalam sastra [1]. Sebuah karya lazimnya berisi gagasan yang luas, struktur yang rumit, serta ditulis dengan medium bahasa yang indah. Ia dibangun dengan sistem tanda bahasa sebagai mediumnya. Sistem tanda bahasa ditingkatkan daya gunanya oleh sastrawan. Setiap kata, frasa, ungkapan, kalimat, bahkan setiap satu kesatuan atau unit yang lebih besar selalu memberikan peluang dan ruang pemaknaan yang tidak tunggal (denotatif). Setiap satuan sistem tanda bahasa dapat menghadirkan berbagai kemungkinan konotasi.

Hoax sebenarnya adalah sebuah tipuan yang diciptakan dengan seni. Hoax juga merupakan kebohongan yang menyamar -sebagai- dan menyamarkan kebenaran. Menurut sejarahnya, esensi hoax merupakan bagian dari tradisi kritik yang disebut satir art hoax (SAH). Satir (satire) adalah salah satu wujud sindiran yang digunakan untuk mengkritik sesuatu, fenomena atau sebuah kondisi tertentu. Dengan demikian, yang dimaksud SAH adalah sebuah kritik yang dikonstruksi dengan seni tipuan atau manipulasi sistem tanda. Nah,

\footnotetext{
${ }^{1}$ Makalah disampaikan pada Seminar Nasional bertajuk "Haoks, Literasi Sastra, dan Kedewasaan Berpolitik", yang dihelat oleh HISKI Komisariat Banyumas, Sabtu 13 April 2019.

2 Teguh Trianton, lulusan Program Doktor PBI UNS, mengajar di Prodi PBSI FKIP UM Purwokerto.
} 
di sinilah kemungkinan dusta atau kebohongan sengaja dibuat untuk tujuan mengkritik dengan satire.

Sastra hoax adalah seni menyampaikan kebenaran secara satire yang dibuat dengan memanipulasi sistem tanda untuk menyembunyikan fakta yang sebenarnya sebagai bentuk ketaklangsungan ekspresi. Manipulasi sistem tanda berlangsung sebagai proses estetik yang mengedepakan sikap etik tertentu. Manipulasi ini didasari dan disadari sebagai sebuah etika penyampain pesan atau maksud yang baik.

\section{Kritik yang HOTS}

Sebenarnya, satire tidak pernah dibangun untuk menipu. Tujuan dari satire adalah untuk mengkritik atau mempertanyakan sebuah fenomena. Dalam konteks sastra, satire dapat dibedakan menjadi dua. Pertama, satire sebagai salah satu jenis karya sastra, lantaran karakteristik dan fungsinya yang mengandung sindiran. Kedua satire sebagai bentuk seni dalam kritik sastra, yaitu sebuah upaya seorang kritikus dalam menyampaikan penilaian terhadap sebuah hasil karya sastrawan. Tujuan utamanya antara lain adalah untuk mengolokolok, menyindir, dan memberikan respon evaluatif terhadap karya tersebut.

Kritik sastra merupakan salah satu bagian dari wilayah studi sastra yang meliputi tiga bidang yaitu; teori sastra, sejarah sastra, dan kritik sastra. Kritik sastra merupakan studi yang membicarakan karya sastra dengan fokus pada penilaian. Kritik sastra merupakan studi mengenai pertimbangan baik atau buruknya hasil kesusastraan. Pertimbangan itu disertai dengan alasan yang logis dan argumentatif mengenai isi dan bentuk karya sastra. Kritik sastra juga dipahami sebagai penjelasan dan penghakiman terhadap kualitas karya sastra [2, 3].

Kritik sastra acap kali dianggap sebagai kecaman terhadap suatu hasil karya, tetapi disertai uraian dan pertimbangan yang logis. Kritik sebenarnya merupakan tanggapan atau pendapat seseorang terhadap objek tertentu. Kritik yang baik hanya dapat ditulis dengan pengamatan yang teliti, perbandingan yang tepat, dan pertimbangan yang adil terhadap baikburuknya kualitas, nilai, dan kebenaran suatu karya. Menulis kritik berarti memberikan panduan yang memadai kepada pembaca untuk menilai kualitas sebuah karya. Kritik sastra yang berkualitas adalah penilaian terhadap karya sastra dengan melibatkan seperangkat konsep dasar atau teori, berbagai sudut pandang, dan genetika teks atau sejarah sastra. Kritik sastra yang demikian akan menghasilkan sebuah penilaian yang koprehensif.

Kritik sastra memiliki aspek pokok yang meliputi; analisis, interpretasi, dan evaluasi atau penilaian. Dengan demikian, dalam konteks taksonomi berpikir, kritik sastra sesungguhnya merupakan aplikasi kongkret dari kemampuan berpikir tingkat tinggi atau Higher Order Thingking Skill (HOTS).

HOTS adalah proses transfer dari sebuah masalah kemudian masalah tersebut dicari solusinya menggunakan cara berpikir kritis. Tingkatan kemampuan berpikir (kognitif) secara umu dibagi menjadi dua, yaitu; cara berpikir tingkat rendah (lower order thiking) yang meliputi; kemampuan mengingat, memahami, dan mengaplikasikan. Sedangkan cara berpikir tingkat tinggi (HOTS) meliputi; menganalisis, mengevaluasi, serta mencipta. Tingkatan HOTS dapat dibagi menjadi empat, yaitu memecahkan masalah, membuat keputusan, berpikir kritis, dan berpikir kreatif. Sebenarnya HOTS akan terjadi ketika individu menerima informasi asing (baru) kemudian memanggil informasi lama yang tersimpan dalam memori $[4,5,6]$. Kedua informasi ini, kemudian dielaborasikan sebagai bekal untuk melakukan interpretasi.

Interpretasi terhadap teks sastra dapat dilakukan dengan cara analisis, parafrase, dan komentar. Interpretasi lazimnya berpusat pada kegelapan, representasi, penggambaran, ambiguitas, atau ketaklangsungan ekspresi dalam penyampaian pesan yang dilakukan dengan penggunaan sistem tanda yang kompleks. Analisis dan penafsiran karya sastra harus dihubungkan dengan penilaian. Aktivitas kritik sastra tersebut tidak dapat dipisah-pisahkan 
sebagai wujud apresiasi tertinggi terhadap karya sastra, semuanya saling erat hubungan dan saling menentukan secara simultan.

Fungsi kritik sastra dapat dibagi menjadi tiga, yaitu untuk mengembangkan ilmu sastra, mengembangkan kesusastraan, dan penerangan masyarakat luas. Kritik sastra dapat membantu penyusunan teori sastra dan sejarah sastra. Ia juga membantu perkembangan kesusastraan suatu bangsa dengan menjelaskan keberadaan karya sastra; mengenai baikburuknya karya sastra dan menunjukkan jangkauan wilayah persoalan karya sastra. Dengan demikian para sastrawan dapat mengambil manfaat dari kritik sebagai bekal untuk mengembangkan tradisi penulisan karya sastra. Kritik sastra menguraikan hasil analisis, menginterpretasi, dan penilaian karya sastra, sehingga dapat dimanfaatkan oleh masyarakat umum dalam memahami dan mengapresiasi karya sastra [7,8].

\section{Literasi dan Multiliterasi}

Literasi merupakan kemampuan seseorang dalam mencari, mengumpulkan, menginterpretasikan, menggunakan, mengevaluasi dan mengkomunikasikan informasi dari berbagai sumber secara efektif. Pada awalnya konsep literasi dimengerti sebagai kemampuan membaca dan menulis saja. Literasi dikaitkan pada kemampuan berkomunikasi lisan dan tulisan semata. Bahkan pada saat deklarasi universal hak asasi manusia (HAM) pendidikan dan literasi didefinisikan sebagai hak dasar setiap individu. "A right primarily understood as a set of technical skills: reading, writing and calculating” [9] . Konsep ini, dalam konteks Indonesia disebut dengan istilah kemelekhurufan, yaitu kemampuan membaca dan menulis.

Seiring dengan perkembangan ilmu pengetahuan dan teknologi, berdampak pada perubahan sistem dan media komunikasi. Puncaknya adalah ditemukannya teknologi digital yang mengenalkan kita pada era konvergensi. Informasi tidak hanya dibagikan dalam bentuk aksara yang hanya dapat dibaca dan ditulis. Konvergensi mengubah informasi vebal menjadi digitalisasi, tipe konten yang berbeda (data, audio, suara, video) diletakkan dalam suatu format yang sama dan dikirim terus menerus melalui berbagai variasi teknologi informasi seperti komputer, handphone, televisi, dan lain-lain. Informasi juga dapat diteruskan pada platform yang berbeda.

Peristiwa fenomenal yang terjadi pada perkembangan komunikasi dan teknologi (1950-an) adalah mnculnya beragam media elektronik seperti telepon, film, radio dan televisi. Disusul pada tahun 1980-an muncul teknologi media digital dan internet. Munculnya media digital dapat memperluas jangkauan informasi dengan kecepatan yang tinggi, telah memimpin -dalam konteks masyarakat informasi- sebuah intelektual baru, semiotik, komunikatif dan perubahan iklim budaya. Ini menandai efek pada perorangan, relasi kerja dan perkembangan sosial [10].

Pada awal kemunculannya, media komunikasi digital ini disebut sebagai new media. Media baru dikelompokan menjadi empat kategori. Pertama, media komunikasi interpersonal seperti telepon, handphone, e-mail. Kedua, media bermain interaktif seperti komputer, video game, permainan dalam internet. Ketiga, media pencarian informasi yang berupa portal atau search engine. Keempat, media partisipasi kolektif seperti penggunaan internet untuk berbagi dan pertukaran informasi, pendapat, pengalaman, dan menjalin hubungan melalui komputer di mana penggunaanya tidak semata-mata untuk alat, namun juga dapat menimbulkan afeksi dan emosional [11].

Perubahan jaman dan kebudayaan manusia berkembang cepat. Manusia dapat memperoleh berbagai informasi melalui berbagai media. Konsep literasi tidak hanya berhenti pada batas keberaksaraan. Istilah literasi beralih menjadi multiliterasi, yaitu many different text types and media that people engage with. It incorporates the different uses of language online, on mobile phones and tablets, and incorporates a broader understanding of text types and audiences $[12,13]$. 
Secara ringkas terdapat empat fase perkembangan literasi. Pertama, literasi klasik yaitu kemampuan membaca, menulis, dan memahami informasi; kedua, literasi audiovisual, yang menghubungkan kepada media elektronik seperti film dan televisi, fokus pada gambar dan rangkaian gambar; ketiga, digitalisasi informasi atau digital literasi yang berasal dari komputer dan media digital; dan keempat, literasi media yaitu sebuah fase konvergensi media yang menggabungkan media elektronik dan media digital. Literasi media ini meliputi beragam bentuk literasi: membaca, menulis, audiovisual, digital dan konvergensi media [10].

Konsep multiliterasi diturunkan dari definisi literasi komprehensif sebagai berikut.

Literacy is the use of socially-, and historically-, and culturally- situated practices of creating and interpreting meaning through texts. It entails at least a tacit awareness of the relationships between textual conventions and their context of use and, ideally, the ability to reflect critically on those relationships. Because it is purpose-sensitive, literacy is dynamic - not static - and variable across and within discourse communities and cultures. It draws on a wide range of cognitive abilities, on knowledge of written and spoken language, on knowledge of genres, and on cultural knowledge [14].

Multiliterasi sesungguhnya timbul sebagai respon dari munculnya beragam moda dalam proses penyampaian pesan dan interpretasi makna. Moda adalah sumber semiotik yang terbentuk secara sosial dan kultural untuk membuat makna. Jenis-jenis moda ini adalah bahasa (lisan, tulis), gambar, musik, gerakan tubuh, video. Moda-moda ini lazimnya digunakan dalam representasi dan komunikasi [15].

Fenomena dan aneka objek merupakan produk aktivitas sosial yang memiliki makna. Masing-masing moda memiliki makna tergantung dari konteks sosialnya. Proses interpretasi makna tidak dapat dilepaskan dari jalinan dan jaringan moda. Dalam konteks ini, makna diinterpretasi berdasarkan multimodalitas. Dengan demikian fenomena-fenomena atau objekobjek yang menjadi pesan akan mendapatkan makna yang lebih komprehensif.

Multimodalitas merupakan pendekatan multi disipliner untuk memahami komunikasi dan representasi lebih dari sekedar peristiwa bahasa. Pendekatan ini dikembangkan untuk menjawab persoalan tentang perubahan dalam masyarakat kontemporer. Pendekatan multimodal memberikan konsep-konsep, metode-metode, dan kerangka kerja untuk pengumpulan dan analisis informasi dalam beragam bentuk seperti gambar, video, gerakan tubuh, bahasa dan sebagainya.

Dengan demikian, multiliterasi adalah kemampuan seseorang dalam mencari, mengumpulkan, menginterpretasikan, menggunakan, mengevaluasi dan mengkomunikasikan informasi dari berbagai sumber dan multimodalitas secara efektif, dengan melibatkan situasi sosial, historis, dan kultural untuk mendapatkan makna yang komprehensif melalui jalinan dan jaringan teks.

\section{Multiliterasi dalam Kritik Sastra}

Di era teknologi digitalisasi informasi seorang pencipta dan pembaca sastra berada dalam sebuah jaringan sistem tanda yang bertingkat-tingkat. Karya yang mereka buat dan baca tidak dapat dipisahkan dari multimodalitas. Oleh sebab itu, prosedur interpretasi dan kritik sastra mengalami babak baru. Pendekatan dalam kritik sastra tidak monodisipliner. Kritik sastra dilakukan dengan pendekatan interdisipliner atau multidisipliner karena persoalan yang ada di dalamnya berkaitan dengan berbagai ilmu pengetahuan. Pendekatan inilah yang memungkinkan praktek studi multiliterasi dalam kritik sastra.

Berdasarkan karakteristiknya, pendekatan interdisipliner ini dapat dibagi menjadi empat jenis pendekatan, yaitu: pendekatan interdisipliner, pendekatan multidisipliner, pendekatan transdisipliner, dan pendekatan krosdisipliner. Interdisipliner adalah interaksi 
intensif antarsatu atau lebih disiplin, baik yang langsung berhubungan maupun yang tidak, melalui program-program penelitian, dengan tujuan melakukan integrasi konsep, metode, dan analisis. Multidisipliner adalah penggabungan beberapa disiplin untuk menjawab atau menyelesaikan masalah tertentu. Transdisipliner adalah upaya mengembangkan sebuah teori atau aksioma baru dengan membangun relasi dan relevansi antarberbagai disiplin [16].

Studi multiliterasi dan interdisipliner dalam konteks kajian sastra merupakan sebuah keniscayaan, sebab karya sastra sesungguhnya merupakan mozaik atau nukilan-nukilan berbagai objek pengetahuan dalam sebuah jaringan teks atau intertektualitas. Konsep hubungan antarteks (intertekstualitas) mengandaikan adanya frame of refference yang lebih terbuka, di dalam setiap memaknai kehadiran stock of knowledge kebenaran ilmiah, mengingat kebenaran setiap teks itu senantiasa berada dalam jalinan perlintasan (transposition) dengan teks-teks lain [17, 18].

Berbagai jenis teks dimanfaatkan sebagai sumber atau bahan interpretasi dan penilaian karya sastra. Prinsip ini sesuai dengan konsep multiliterasi bahwa berbagai modal dapat digunakan dalam studi ilmiah. Berbagai genre teks sangat penting untuk dijadikan bahan analisis. Perkembangan ilmu pengetahuan dan teknologi mendorong terciptanya beragam teks dengan berbagai moda. Teks direproduksi dalam format digital elektronik; verbal, audial, dan visual, teks dalam bentuk film atau video, dapat diakses secara online, dan sebagainya. Oleh karena itu, interpretasi terhadap sebuah teks sastra niscaya dilakukan secara multiliterasi melibatkan berbagai perangkat, pendekatan, fitur, dan multidisiplin dalam sebuah jaringan intertekstual.

Prinsip multimodal menjadi dasar bagi perkembangan model pembelajaran literasi. Multimodal adalah konsep "meaning and knowledge are built up through various modalities in- cluding images, texts, symbols, and interactions". Konsep multimodal dalam pembelajaran bahasa adalah language arts education can no longer ignore the way that our social, cultural, and economic world now require facility with texts and practice involving the full range of representational modes $[19,20]$.

Konsep multimodal ini pada tahun 1996 dikenalkan menjadi konsep multiliterasi. Manusia tidak hanya membaca atau menulis, namun mereka membaca dan menulis dengan genre tertentu yang melibatkan tujuan sosial, kultural, dan politik. Dalam upaya peningkatkan kompetensi multiliterasi, penggunaan grafik, gambar, setting tulisan, foto, presentasi, gestur, bermain drama, baik dalam bentuk cetak maupun elektronik menjadi sumber dan media pembelajaran yang menarik. Mode penting digunakan sebagai bentuk sumber sosial dan kultural untuk melakukan pemaknaan [21, 22, 23, 24, 25, 26, 27].

Ada empat dimensi multiliterasi. Pertama, situated practice, yang menggambarkan pengalaman hidup seseorang. Kedua, overt instruction, yang melibatkan metabahasa untuk mendekonstruksi konsep dan cara multimodal dimana makna dikonstruksi. Ketiga, critical framing of the cultural and social context, dimana makna dikenalkan dan dipahami sebagai konteks kultural dan sosial. Keempat, transformed practice, sebagai upaya untuk mentransformasikan makna dalam dimensi sosial dan kultural [21].

Praktik multiliterasi dalam kritik sastra didasarkan pada aspek multimodal literasi yang meliputi kompetensi linguistik, kompetensi visual, kompetensi audio, kompetensi gestural, dan kompetensi spasial. Studi karya sastra akan dilakukan dengan menghubungkan berbagai teks, sistem tanda, dan pesan yang relevan. Seorang kritikus niscaya akan menggunakan seluruh pengetahuannya yang telah diperoleh melalui berbagai modalitas untuk menginterpretasi karya sastra. Karya sastra akan dihubungkan dengan berbagai teks seperti film, drama, teater, program televisi sebagai bahan analisis. Kompetensi linguistik memberikan kontribusi pada analisis terhadap bahasa lisan sebagaimana dalam kehidupan sehari-hari baik struktur, organisasi, gaya bahasa, kepribadian tokoh, dan konteks kultural masyarakat dalam kehidupan tokoh. Kompetensi spasial berkenaan dengan analisis terhadap 
penggunaan ruang dan pengaruhnya pada karakter tokoh. Kompetensi gestural menitikberatkan pada analisis terhadap aksi yang diperankan oleh tokoh. Kompetensi visual berkenaan dengan bagaimana sesuatu dapat diamati baik hal, sikap atau barang.

\section{Penutup}

Hakikat sastra adalah produk budaya, ia tidak pernah ditulis dalam situasi yang nihil budaya. Proses penciptaan karya sastra secara otomatis (niscaya) melibatkan berbagai pengetahuan (multidisipliner) yang dimiliki oleh pengarang. Multidisipliner ini diperoleh dari multimodalitas dengan multiliterasi. Oleh karena itu, karya sastra harus ditempatkan dalam jaringan teks yang relevan. Karya sastra juga harus diinterpretasi dengan melibatkan beragam disiplin pengetahuan yang berkenaan dengan objek studi, dihubungkan (intertekstualitas) dengan beragam teks dari berbagai moda. Proses inilah yang disebut sebagai kritik sastra dalam perspektif multiliterasi (HOTS).

Kritik sastra memiliki kontribusi positif bagi perkembangan sastra sebagai cermin perkembangan peradaban manusia. Oleh sebab itu perspektif kritik sastra perlu diselaraskan dengan perkembangan budaya. Kritik tidak lagi bersifat monodisiplin. Kritik yang baik adalah kritik yang dibuat dengan melibatkan segenap jalinan teks yang relevan, dari berbagai mode, dan multidisipliner. Karya kritik sastra menjadi wadah pengungkapan penilaian terhadap karya sastra yang bersifat menyeluruh, simultan, dan komprehensif. Dengan demikian, hoax sebagai seni dalam sastra dapat dibongkar guna mendapatkan tafsir dan penilaian yang komprehensif.

\section{Daftar Referensi}

[1] Dahana, R.P. Kebenaran dan Dusta Dusta Dalam Sastra. Magelang; Indonesia Tera, 2001.

[2] Wellek, R., dan A. Warren, Teori Kesusastraan, (Terj. Melani Budianta), Jakarta: Gramedia, 2014.

[3] Abrahm, M.H. A Glosary of Literary Terms, New York: Holt Rinehart and Winston, 1981.

[4] Anderson, L.W., \& Krathwohl, D.R. Kerangka landasan untuk pembelajaran, pengajaran, dan asesmen (terjemahan Agung Prihantoro). New York: Addition Wesley Longman, 2010. (buku asli diterbitkan tahun 2001).

[5] Bogan, Y. K.H., \& Porter, R. C. On the Ball with Higher-Order Thinking. Pro Quest Research Library, 36, 46-47, 2005.

[6] Costa, A. L. Developing Minds: Programs for Teaching Thinking (Rev.Ed). Volume 2. Alexandria: ASCD, 1991.

[7] Pradopo, R.D. Prinsip-Prinsip Kritik Sastra, Yogyakarta: UGM Press, 2011.

[8] UNESCO, The Plurality Of Literacy And Its Implications For Policies And Programmes. Paris: United Nations Educational, Scientific and Cultural Organization, 2004. Tersedia di http://unesdoc.unesco.org/images/0013/001362/136246e.pdf, (Diakses 28 Desember 2016).

[9] Baran, Stanley J. Introduction To Mass Communication: Media Literacy and Culture, Network: The Mc. Graw - Hill Companies, 2004.

[10] Mc Quail, D. Communication and the Public Interst, London: Sage Publications, 2002.

[11] Perry, K. "What is Literacy? -A critical overview of sociocultural perspectives," Journal of Language and Literacy Education [Online], 8(1), pp. 50-71, 2012. Available at http://jolle.coe.uga.edu/wp-content/uploads/2012/06/What-is-Literacy KPerry.pdf

[12] Fielding, R. "Considering biliteracy and multiliteracies in the primary classroom", dalam Johnston, J. (Ed), Contemporary issues in Australian literacy teaching, Brisbane: Primrose Hall Publishing Group, 2012.

[13] Kitson, L., Fletcher, M. and Kearney, J. "Continuity and Change in Literacy Practices: A Move towards Multiliteracies" in The Journal of Classroom Interaction, 41/42, (2/1), pp. 29-41, 2007. Stable http://www.jstor.org/stable/23869446. Accessed: 16-08-2017.

[14] Kern, R. Literacy and Language Teaching, Oxford: Oxford University Press, 2000. 
[15] Kress, G. Carey Jewitt, Jon Ogborn and Charalampos Tsatsarelis, Multimodal Teaching and Learning: The rhetorics of the science Classroom, Continuum: London and New York, 2001.

[16] Prentice, A.E. "Introduction" dalam Information Science - The Interdisciplinary Context, (ed. J. M. Pemberton dan A.E. Prentice), New York : Neal-Schuman Publishers, 1990.

[17] Kristeva, J. Revolution in Poetic Language (European Perspectives Series), Columbia: Columbia University Press, 1974.

[18] Kristeva, J. Desire in Language: A Semiotic Approach to Literature and Art, Columbia: Columbia University Press, 1979.

[19] Vasquez, V. Getting Beyond "I Like the Book": Creating Space for Critical Literacy in K-6 Classrooms, Newark, DE: International Reading Association, 2003.

[20] Siegel, M. "Rereading the Sign: Multimodal Tranformations in the Field of Literacy Education" in Language Arts, 84 (1), 2006. Available at www.proquest.umi.pqd/web

[21] New London Group, A Pedagogy of Multiliteracies: Designing Social Futures, Harvard Educational Review, 66, 1996.

[22] Coughlan, S. "Advocating for the Arts in an Age of Multiliteracies" in Language Arts, 86 (2), 2008. Available at www.proquest.umi.pqd/web

[23] Bazemer, J. \& Kress, G. "Writing in Multimodal Texts: A Social Semiotic Account of Designing for Learning," in Written Communication, 25 (2), 2008.

[24] Tan, J. Pei-Ling and McWilliam, Erica L., "From literacy to multiliteracies: diverse learners and pedagogical practice", Pedagogies: An International Journal, 4 (3), pp. 213-225, 2009.

[25] Barron, N. G. Review Buku: "Multiliteracies: Literacy: Learning and the Design of Social Futures," in Technical Communication Quarterly, Autumn, 16 (4), 2007.

[26] Hasset, D. D., dan Jen Scoot Cur-wood. "Theories and Practice of Multimodal education: The Instructional Dynamics of Picture Book and Primary Classroom" in The Reading Teacher 63 (4), 2009, International Reading Association. Available at www.proquest.umi.pqd/web

[27] Graham, M. S., Sheila Benson, Lisa Storm Fink, "A Springboard Rather Than a Bridge: Diving into Multimodal Literacy" in English Journal (High School Edition) Urbana: 200 (153) November 2010. 